Title:

Mineralogical and Geochemical Aspects of Mineral-Induced Disease

Author(s):

George Guthrie, EES-1

Robert Raymond, EES-1

RECEIVED

APR 011996

Brooke Mossman, University of Vermont Umberto Saffiotti

Ann Aust

Submitted to:

DOE Office of Scientific and Technical Information (OSTI)

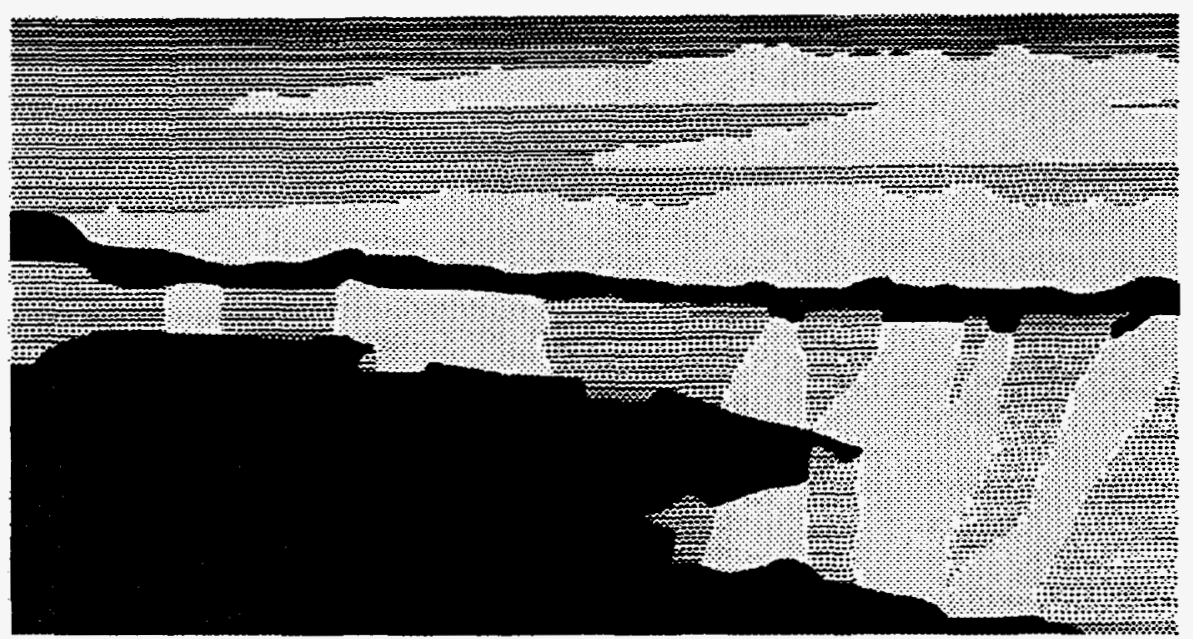

Los Alamos National Laboratory, an affirmative action/equal opportunity employer, is operated by the University of California for the U.S. Department of Energy under contract W-7405-ENG-36. By acceptance of this article, the publisher recognizes that the U.S. Govemment retains a nonexclusive, royaltytree license to publish or reproduce the published form of this contribution, or to allow olters to do so, for U.S. Government purposes. The Los Alamos National Laboratory requests that the publisher identify this article as work performed under the auspices of the U.S. Department of Energy. 


\section{DISCLAIMER}

Portions of this document may be illegible in electronic image products. Images are produced from the best available original document. 



\title{
Mineralogical and Geochemical Aspects of Mineral-Induced Disease
}

George Guthrie*, Robert Raymond, Brooke Mossman (University of Vermont), Umberto Saffiotti, and Ann Aust

\begin{abstract}
This is the final report of a three-year, Laboratory-Directed Research and Development (LDRD) project at the Los Alamos National Laboratory (LANL). Many minerals are known to cause disease following inhalation, including asbestos, silica, zeolites, and clays. The mineralogical properties that determine toxicity are not known, hindering effective risk assessment. Consequently, many minerals that do not pose risks are controlled excessively and many minerals that do pose risk remain uncontrolled. We are integrating mineralogy and biology in an interdisciplinary scientific investigation of the mechanisms of mineral-induced disease. Our biological endpoints include the formation of ferruginous bodies and chemical signaling (e.g., production of cytokines or active oxygen species) by cells; our mineralogical variables include structure, composition, and surface properties. We are also determining what information about the biological reaction is preserved in the mineral surface.
\end{abstract}

\section{Background and Research Objectives}

The induction of diseases by inhaled minerals is a problem traditionally viewed as only biological in nature. However a thorough understanding of this environmental issue requires an interdisciplinary approach encompassing mineralogical and geochemical factors.

The biochemical reactions important in mineral-induced pathogenesis have been and continue to be studied extensively, and many of the potentially necessary steps in the disease process have been identified. For example, DNA damage (which is a necessary step in carcinogenesis) can result from the generation of active oxygen species by a series of redox reactions that are induced in some way by the mineral. Relatively little is known, however, about the mineralogical and geochemical processes important in pathogenesis. The biochemical reactions

*Principal investigator, e-mail: gguthrie@lanl.gov 
occur at or near mineral surfaces, so these geoscientific issues are necessary components of mechanistic models of mineral-induced disease.

The lack of understanding about the geoscientific issues results from the non-participation of geoscientists in this area of research. Geoscientists have the potential to bring unique perspectives to this problem by combining their principles and approaches with those of bioscientists. That was the primary goal of this project: to launch a collaborative effort with bioscientists in which we apply our geoscientific expertise to develop a mechanistic model for the induction of diseases by minerals. In this project, we were trying to answer several questions:

- What mineralogical properties are important in pathogenesis?

- What geochemical processes are important in pathogenesis?

- Can geological principles be used to infer details of mineral-fluid reactions in the lung?

There is no detailed mineralogical and/or geochemical model to explain how minerals induce disease. In the absence of such a model, the biological activities of minerals are determined empirically. Evaluation of a mineral's pathogenic potential (or ability to induce disease) is traditionally achieved by expensive animal testing. However, results from such experiments are mineral-specific, since the data provide little information on the biological activity of other minerals. A mineral's properties can vary extensively between samples, so the data are often sample-specific as well. A sound model is needed to permit the evaluation of a sample's health risk given its physical/chemical characteristics.

One barrier to the development of a model is the paucity of mineralogical and geochemical data relevant to mineral-fluid interactions in a biological environment. Several biochemical mechanisms have been proposed, each of which relates to complementary geochemical mechanisms. Unfortunately, these geochemical mechanisms are seldom probed. The goal of this project was to identify these mechanisms.

\section{Importance to LANL's Science and Technology Base and National R\&D Needs}

This research is important to LANL and the nation for several reasons. First, minerals are integral aspects of our occupational and non-occupational lives and we are exposed to them daily. Many minerals are suspected pulmonary toxicants and some have been shown to induce cancer and other lung diseases in humans. If we are to exploit minerals in a safe but reasonable manner, it is essential to develop a complete understanding of the processes related to mineralinduced disease. 
Second, extensive resources have been devoted to fixing a problem related to mineral toxicity that we still do not fully understand. As a nation, we plan to spend $\$ 100$ billion to remove asbestos from public buildings, a policy that is based on the health risks associated with amphibole asbestos. However, over 90 percent of the asbestos used in this country is chrysotile, a type of asbestos that has not been definitively shown to induce mesothelioma (a rare type of asbestos-related cancer) in humans. Our incomplete understanding of the mineralogical and geochemical aspects of mineral-induced cancer has resulted in the regulation of all asbestoses (irrespective of mineral species) based on the risk associated with the most toxic type. Clearly, mineral hazards are considered to be an important national issue, given the response to asbestos alone.

Third, LANL and the Department of Energy (DOE) are currently involved in the investigation of Yucca Mountain as a site for a potential high-level radioactive-waste repository. A situation analogous to asbestos may arise at Yucca Mountain, where the fibrous zeolite mordenite occurs as a common alteration mineral throughout the tuffs. Another fibrous zeolite (erionite) was recently shown to be the most toxic mineral to date, and it has raised concerns over the potential health hazards of fibrous zeolites in general. Zeolites (including both mordenite and erionite) are critical components of the processing of crude oil (they are used as cracking catalysts), and they are very important industrial commodities in other applications as well. To avoid a blanket condemnation of zeolites that may be unwarranted (as occurred with asbestos), it is essential that one determine the mineralogical and geochemical properties that control toxicity.

\section{Scientific Approach and Results}

During the course of this project, we have made substantial progress towards our goal of linking biological and geological issues. Our progress falls into two categories: developing an interdisciplinary field and collaborative research.

\subsection{Developing an interdisciplinary field}

Our unique approach is linking geoscientific-based research with biological endpoints. A key component of the success of this approach has been the integration of our effort with the efforts of bioscientists. We cannot pursue the geological aspects of this problem separately from the biological aspects, as has typically been done in the past.

To overcome this interdisciplinary hurdle, we organized and convened an international workshop on the health effects of minerals during the first year of this project. This workshop was part of the Mineralogical Society of America's short-course series, and the proceedings were published as part of the Reviews in Mineralogy. Several of the chapters were contributions from Los Alamos scientists, and the book was co-edited by one of us. The two and a half day short 
course was attended by $\sim 75$ scientists from both the geological and biological communities, and we developed a number of important biological collaborations that we will exploit in our research over the next year. The book will be reviewed by Chest, the magazine of the American College of Chest Physicians (a major professional society in pulmonary science).

This workshop helped us to gain recognition in the biological community about the need for our interdisciplinary approach in this research area. It resulted in a number of invitations to serve on expert panels (e.g., an expert panel on toxicology at an international meeting on the health effects of silica), to participate in the review process for NIH grants (including serving on a study group), to organize symposia at several national meetings, to present numerous invited talks (including two keynote addresses and several talks at biological meetings), and to participate in an NSF working group tasked with defining a new interdisciplinary program for geoscience.

\subsection{Collaborative research}

a. Mineralogical Analysis of Material Used in Biological Assays. One of the most important factors determining a sample's biological activity is its mineral content, i.e., the types and abundances of mineral species it contains. In principle, one can gain insight into the relationship between mineral species and biological activity by perusing the biological literature. The biological activities of numerous mineral species have been studied to some extent. When one does this, it becomes clear that there is a wide range of reported properties for a particular mineral species [1]. Some of this variation may be explained by true variations in properties within a mineral species. However, we were concerned that some may be due to mineral impurities in the samples, because mineral standards are not available for many of the species of interest to the biological community. For this reason, we have applied recently developed techniques in quantitative analysis of minerals by $\mathrm{x}$-ray diffraction (i.e., the Rietveld method) to the analysis of several mineral samples used in biological experiments.

Our investigations were done collaboratively with several bioscientists, who provided aliquots from samples on which they had published data. Some of the mineral samples were relatively pure (particularly some of the quartz samples). However, some of the samples were highly impure, making the interpretation of the biological activities of those mineral species impossible. Mordenite (a fibrous zeolite) is a good example of this problem. The numerous biological studies that have been published on mordenite's biological activity can be linked to only two specimens, which were provided by Mossman. Neither specimen contained more than 50 percent mordenite [2]. This makes interpretation of the biological activity of mordenite impossible, because the behavior of mixtures of minerals is not known (i.e., we don't know if mixtures of minerals behave antagonistically, additively, or synergistically.) 
b. Surface Analysis of Riebeckite. One of our main efforts was an investigation of the changes in the surfaces of amphiboles following interaction with a physiological fluid.

Amphiboles are known to cause the formation of active oxygen species, and Aust and coworkers have shown that this process can be affected by the presence of chelating agents. They have shown that iron released from minerals (i.e., the dissolution behavior of a mineral) may be important in the generation of active oxygen species. Chelating agents (such as EDTA and deferoxamine) can enhance the release of iron from the mineral, which promotes a redox cycle (the Fenton reaction) to catalyze the formation of the hydroxyl radical $(\bullet \mathrm{OH})$. We built upon her work by determining the changes to the mineral surface following interaction with the fluid. We used a combination of imaging (scanning electron microscopy or SEM) and compositional analysis (x-ray photoelectron spectroscopy or XPS) to characterize the surface morphology and composition as a function of alteration, which allowed us to determine some aspects of how the mineral reacts with the lung [3].

c. Formation of Ferruginous Bodies. Some minerals become coated with an iron-rich material following deposition in the lung, and the presence of these ferruginous bodies in lung or sputum is often used as an indication of asbestos exposure. These bodies have very characteristic morphologies, which are suggestive of a mineralogically controlled formation mechanism. We believe these ferruginous bodies result from a mineral-fluid interaction that occurs in the lung, possibly involving interaction between ferritin and the mineral surface.

We have been attempting to grow ferruginous bodies experimentally using solutions of ferritin+mineralsthydrogen peroxide. These experiments are ongoing, but our preliminary results are encouraging. Particles appear to develop an iron-rich coating preferentially at the ends of the fibers. We eventually hope to show that mineral-catalyzed redox processes occurring preferentially at the ends of amphibole fibers can denature protein. The significance of this work is twofold. First, if we can reproduce these bodies in a cell-free system, we will have demonstrated that minerals control at least some biochemical processes in the lung. Second, the process we are investigating involves mineral-catalyzed redox, which may be directly relevant to the generation of free radicals in the lung as well as to various redox processes in geological environments.

d. Induction of Proto-Oncogenes by Cation-Exchanged Zeolites. Finally, some recent advances we have made involve understanding some aspects about how minerals may activate genes. In collaboration with Mossman's group at the University of Vermont, we are investigating the induction of early proto-oncogenes (c-fos and c-jun) by cation-exchanged erionite. Our goal is to determine if minerals can buffer the cation content near a cell's surface and thereby affect its functions. Preliminary results are encouraging: erionite does induce these 


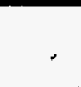


genes, and the different cation-exchanged samples have different activities. We hope to extend this work to an overall understanding of "zeolitic molecular biology."

\title{
References
}

[1] Guthrie, G.D. Jr., "Biological Effects of Inhaled Minerals," Am. Mineral., 77, 225-243 (1992).

[2] Guthrie, G.D., Jr., "Mineral Characterization in Biological Studies," in G.D. Guthrie, Jr. and B.T. Mossman (Eds.), Health Effects of Mineral Dusts, p. 251-273. Min. Soc. Am., Washington (1993).

[3] Werner, A.J., Hochella, M.F., Jr., Guthrie, G.D., Jr., Rimstidt, J.D., Aust, A.E., and Hardy, J.A., "Crocidolite Dissolution in the Presence of Fe Chelators: Implications for Mineral-Induced Disease," Am. Mineral (1995).

\section{DISCLAIMER}

\begin{abstract}
This report was prepared as an account of work sponsored by an agency of the United States Government. Neither the United States Government nor any agency thereof, nor any of their employees, makes any warranty, express or implied, or assumes any legal liability or responsibility for the accuracy, completeness, or usefulness of any information, apparatus, product, or process disclosed, or represents that its use would not infringe privately owned rights. Reference herein to any specific commercial product, process, or service by trade name, trademark, manufacturer, or otherwise does not necessarily constitute or imply its endorsement, recommendation, or favoring by the United States Government or any agency thereof. The views and opinions of authors expressed herein do not necessarily state or reflect those of the United States Government or any agency thereof.
\end{abstract}




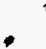

, 